\title{
(6) OPEN ACCESS \\ Does pulse oximeter use impact health outcomes? A systematic review
}

\author{
Abigail J Enoch, ${ }^{1}$ Mike English, ${ }^{2,3}$ Sasha Shepperd ${ }^{1}$
}

\begin{abstract}
${ }^{1}$ Nuffield Department of Population Health, University of Oxford, Oxford, UK

${ }^{2}$ KEMRI-Wellcome Trust

Research Programme, Nairobi, Kenya

${ }^{3}$ Nuffield Department of Medicine, University of Oxford, Oxford, UK

Correspondence to Abigail J Enoch, Nuffield Department of Population Health, Richard Doll Building, Old Road Campus,

Headington, Oxford OX3 7LF, UK; abigail.enoch@seh. ox.ac.uk
\end{abstract}

Received 25 August 2015 Revised 21 October 2015 Accepted 24 October 2015 Published Online First 23 December 2015

\section{SLinked}

- http://dx.doi.org/10.1136/ archdischild-2015-310055

\section{CrossMark}

\footnotetext{
To cite: Enoch AJ,

English M, Shepperd S. Arch

Dis Child 2016;101:

694-700.
}

\section{ABSTRACT}

Objective Do newborns, children and adolescents up to 19 years have lower mortality rates, lower morbidity and shorter length of stay in health facilities where pulse oximeters are used to inform diagnosis and treatment (excluding surgical care) compared with health facilities where pulse oximeters are not used?

Design Studies were obtained for this systematic literature review by systematically searching the Database of Abstracts of Reviews of Effects, Cochrane, Medion, PubMed, Web of Science, Embase, Global Health, CINAHL, WHO Global Health Library, international health organisation and NGO websites, and study references.

Patients Children 0-19 years presenting for the first time to hospitals, emergency departments or primary care facilities.

Interventions Included studies compared outcomes where pulse oximeters were used for diagnosis and/or management, with outcomes where pulse oximeters were not used. Main outcome measures: mortality, morbidity, length of stay, and treatment and management changes.

Results The evidence is low quality and hypoxaemia definitions varied across studies, but the evidence suggests pulse oximeter use with children can reduce mortality rates (when combined with improved oxygen administration) and length of emergency department stay, increase admission of children with previously unrecognised hypoxaemia, and change physicians' decisions on illness severity, diagnosis and treatment. Pulse oximeter use generally increased resource utilisation. Conclusions As international organisations are investing in programmes to increase pulse oximeter use in lowincome settings, more research is needed on the optimal use of pulse oximeters (eg, appropriate oxygen saturation thresholds), and how pulse oximeter use affects referral and admission rates, length of stay, resource utilisation and health outcomes.

\section{INTRODUCTION}

In newborns, children and adolescents hypoxaemia is associated with increased risk of death, and is a common complication of bronchiolitis, pneumonia, asthma and other serious conditions (eg, sepsis). ${ }^{1-4}$ Pulse oximetry is a low-cost intervention that could reduce child mortality, in line with Millennium Development Goal 4, by enabling early detection of hypoxaemia and improving accurate diagnosis, thereby increasing the chance of prompt, effective treatment.

Despite the potential to improve health outcomes, pulse oximeters are often not available, particularly in low-income settings. For example, only $38 \%$ of Nigerian tertiary hospitals and 3 of 22 Kenyan hospitals providing physician internship

\section{What is already known on this topic}

- Hypoxaemia is a common complication of pneumonia, bronchiolitis, asthma and sepsis and is associated with increased risk of death in children.

- Pulse oximeters are a low-cost intervention that could help reduce child mortality by more effectively diagnosing and monitoring children with hypoxaemia.

- Pulse oximeters are often not available or not used in low-income settings, but several international projects aim to increase their availability and use.

\section{What this study adds}

- The evidence, while low quality, suggests pulse oximeter use may improve children's mortality rates, morbidity measurement, hospital length of stay and admission of hypoxic children.

- In the included studies, pulse oximeters were often important for physician's clinical decision-making about children's treatment and management, and their use generally increased resource utilisation.

- More research is needed on optimal thresholds to use for hypoxaemia definitions, and on how pulse oximeter use affects resource utilisation and impacts health outcomes.

training had pulse oximeters in 2011 and 2012, respectively. ${ }^{5} 6$ To promote access, pulse oximeters have been designed for low-income settings, for example, Lifebox, a low-cost, robust, portable, battery-operated oximeter. ${ }^{7}$ Other designs deliver pulse oximeter results to smartphones, using their spread to remote areas. ${ }^{8}$ Initiatives supporting pulse oximeter uptake include the WHO's Global Pulse Oximetry Project, Lifebox donations, and the BMJ Christmas Appeal. ${ }^{7} 910$

Evidence suggests that pulse oximeters identify 20-30\% additional hypoxic children compared with using clinical signs alone, for example, grunting and depressed consciousness, which can be imprecise. ${ }^{11}$ However, evidence of an association between hypoxaemia and mortality is not necessarily evidence that pulse oximetry implementation improves outcomes, particularly taking a broad health system perspective, when health worker actions, characteristics of children and health 
facilities, and additional resources, all interact to impact outcomes.

In the complex world of health systems, pulse oximetry could lead to improved health outcomes and system efficiencies, and reduced resource use, by helping health workers promptly diagnose children and initiate treatment, and by improving diagnostic accuracy, thereby preventing unnecessary admissions and treatments. Alternatively, pulse oximetry could lead to unnecessary admissions, treatment, referrals, and/or discharge delays, if thresholds for admission, referral or intervention are inappropriate.

As pulse oximetry availability increases at primary and community care levels in low-income countries, understanding the health system implications is increasingly important, particularly how pulse oximetry impacts resource utilisation. In high-income countries, guidance for routine screening with pulse oximetry is inconsistent, with some suggesting it is unhelpful. ${ }^{12-17}$ Debate also remains about optimum hypoxaemia definitions, especially at altitude. ${ }^{2} 18-22$

We therefore reviewed the evidence on how pulse oximetry introduction impacts health and service use outcomes.

\section{METHODS}

We addressed the question "Do newborns, children and adolescents aged up to 19 years have lower mortality rates, lower morbidity, and shorter length of stay where pulse oximeters are used to inform diagnosis and treatment (excluding operative surgical care) compared with where pulse oximeters are not used?" Our secondary research question was, "What proportion of newborns, children and adolescents are given oxygen therapy where pulse oximeters are used compared with where pulse oximeters are not used."

Studies were included if they recruited newborns, children and/or adolescents aged up to 19 years, presenting for the first time to a hospital, emergency department (ED), or primary care facility, regardless of setting. Studies assessing pulse oximeters in screening healthy newborns before discharge, or monitoring, for example, during surgery were excluded.

We included studies with at least one intervention group in which a pulse oximeter reading was taken and at least one control group in which pulse oximetry was not used. We included studies reporting mortality, morbidity (illness severity, ie, pneumonia severity scores, disability at discharge) and length of stay. Descriptive studies were excluded.

We systematically searched the Database of Abstracts of Reviews of Effects, Cochrane, Medion, PubMed, Web of Science, Embase, Global Health, CINAHL and WHO Global Health Library, with no language restrictions (Search terms-see online supplementary appendix I). Study references were checked. Websites of non-governmental organisations, health organisations and development organisations were searched for unpublished reports using 'pulse oximeter' and 'pulse oximetry'. Topic experts were contacted for additional materials.

Studies that were not relevant based on title/abstract were excluded. We read the remaining studies' full texts and excluded those not fulfilling the inclusion criteria. All full texts were read by a second person, and if inclusion was uncertain, a third. We extracted data using a tailored Cochrane data collection form and assessed risk of bias using the Cochrane ACROBAT tool. ${ }^{23} 24$

We intended to calculate risk ratios, mean differences and CI's, and if possible pool data within subgroups and conduct a meta-analysis. However, due to the small number of studies and the study design/outcome variability this was not possible.
Instead we narratively describe the evidence using a structured approach while drawing insights where possible, a standard strategy in such situations.

\section{RESULTS}

\section{Search results}

We found 7992 reports after removing duplicates and screened all titles and abstracts, and the full texts of 17 potentially relevant studies. Five studies, ${ }^{25-29}$ all uncontrolled before-after studies (without independent comparison groups), were included (see figure 1).

\section{Risk of bias}

Table 1 demonstrates each study's risk of bias.

\section{Intervention effects}

Only five eligible studies were included, all uncontrolled beforeafter studies at high risk of bias; our confidence in the effect estimates is therefore limited with a high level of uncertainty.

\section{Mortality rates}

Duke et $a{ }^{27}$ reported that mortality rates for children with pneumonia at five Papua New Guinea hospitals decreased by $35 \%$ after services were reorganised and pulse oximeters, oxygen concentrators and training were introduced. It is not possible to determine how much of this mortality improvement was due to pulse oximetry versus the provision of training, oxygen systems and other changes.

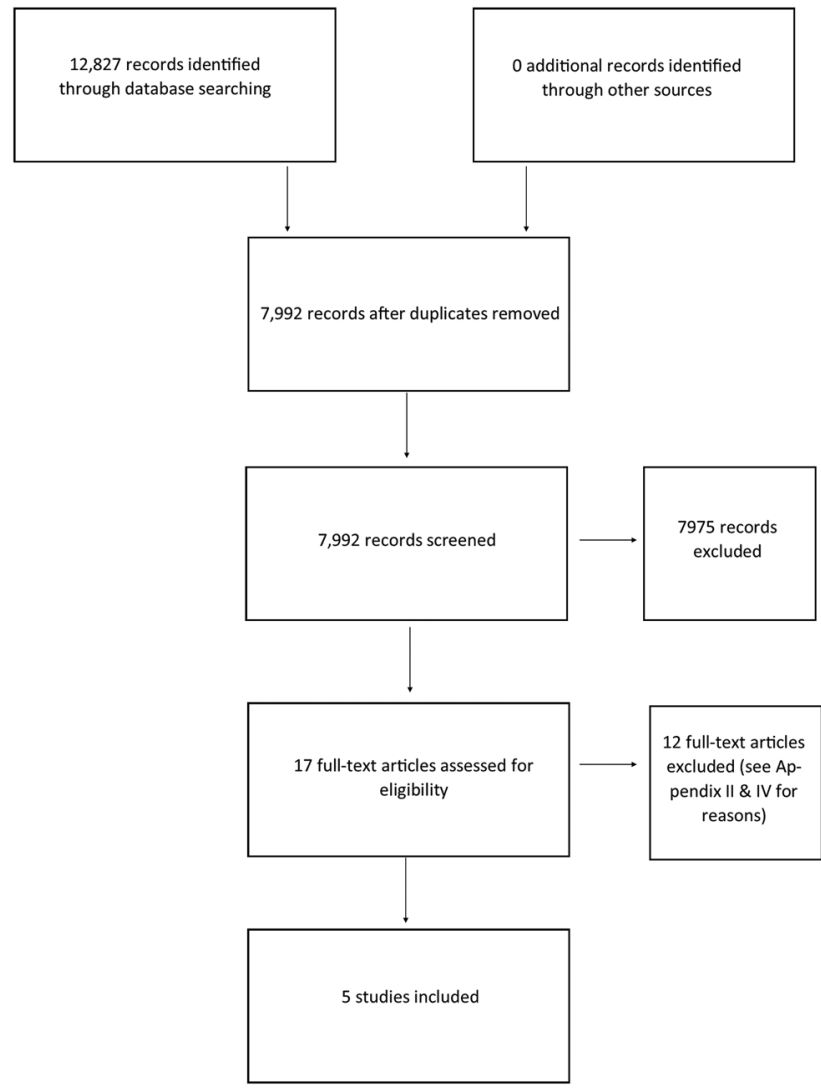

Figure 1 Flow chart showing the study selection process. See online supplementary appendix II for the Characteristics of Included Studies table and online supplementary appendix III for the Characteristics of Excluded Studies table. 
Table 1 Risk of bias ratings for each domain for each study

\begin{tabular}{|c|c|c|c|c|c|c|c|c|}
\hline Study & $\begin{array}{l}\text { Bias due to } \\
\text { confounding }\end{array}$ & $\begin{array}{l}\text { Bias in } \\
\text { selection } \\
\text { of participants }\end{array}$ & $\begin{array}{l}\text { Bias in } \\
\text { measurement } \\
\text { of interventions }\end{array}$ & $\begin{array}{l}\text { Bias due to departures } \\
\text { from intended } \\
\text { interventions }\end{array}$ & $\begin{array}{l}\text { Bias due to } \\
\text { missing data }\end{array}$ & $\begin{array}{l}\text { Bias in } \\
\text { measurement } \\
\text { of outcomes }\end{array}$ & $\begin{array}{l}\text { Bias in selection } \\
\text { of the reported } \\
\text { result }\end{array}$ & Overall \\
\hline Anderson et $a l^{25}$ & Moderate & Moderate & Low & Low & Low & Serious & Serious & Serious \\
\hline Choi et $a l^{26}$ & Moderate & Low & Low & Moderate & Moderate & Moderate & Low & Moderate \\
\hline Duke et $a l^{27}$ & Serious & Moderate & Low & Serious & Moderate & Moderate & Moderate & Serious \\
\hline Maneker et $a l^{28}$ & Moderate & Serious & Low & Low & Low & Serious & Low & Serious \\
\hline Mower et $a l^{29}$ & Moderate & Serious & Low & Low & Low & Serious & Low & Serious \\
\hline
\end{tabular}

\section{Morbidity}

Three studies assessed whether pulse oximeters influence physicians' clinical decision-making. Paediatric physicians assessed children presenting to an ED and decided their treatment before and after obtaining their pulse oximeter results. ${ }^{25} 2829$ Studies defined hypoxaemia differently and their physicians used different oxygen saturation $\left(\mathrm{SaO}_{2}\right)$ thresholds to indicate necessary treatment. No independent controls were included, which increased the risk of bias, as did the study designs' accentuation of pulse oximeters' value in the clinical process by presenting oximeter results to physicians after their initial evaluations.

No studies directly measured morbidity; however, two examined whether pulse oximeters facilitate morbidity measurement (illness severity scores and diagnosis). Anderson et al, ${ }^{25}$ asked physicians to record illness severity assessments, on a 5-point scale, for ill children presenting to the paediatric ward, excluding those with minor orthopaedic/surgical injuries, before and after obtaining pulse oximeter results. Physicians changed 53\% of children's scores; two-thirds of these scores were reduced. Physicians in Mower et al, ${ }^{29}$ changed the diagnoses in $8 \%$ of children with $\mathrm{SaO}_{2}<95 \%$ and $0.7 \%$ of children with $\mathrm{SaO}_{2}$ $\geq 95 \%$ after receiving pulse oximeter results.

Length of stay and influence on admission rates

In Choi and Claudius, ${ }^{26}$ the average time spent in a paediatric ED triage when pulse oximeters were used was $17 \%$ less than in the same ED a year previously, when pulse oximeters were not used.

Maneker et al, ${ }^{28}$ reported that $46 / 69$ children (67\%) who had low $\mathrm{SaO}_{2}\left(\mathrm{SaO}_{2}<92 \%\right)$ had not been clinically expected to have low $\mathrm{SaO}_{2}$, while $23(33 \%)$ had been expected to have low $\mathrm{SaO}_{2}$. After obtaining pulse oximeter results, physicians admitted 13/46 (28\%) of children with unexpectedly low $\mathrm{SaO}_{2}$ (who would have been discharged without pulse oximetry) and admitted $1 / 23(4 \%)$ of children who expectedly had low $\mathrm{SaO}_{2}{ }^{28}$ Mower et $a l,{ }^{29}$ found that after receiving pulse oximeter results, physicians admitted 5 additional children of the 305 who had $\mathrm{SaO}_{2}<95 \%(2 \%)$ and 5 additional children of the 1822 who had $\mathrm{SaO}_{2} \geq 95 \%(0.3 \%) .{ }^{29}$

\section{Secondary research question}

Management plans changed for 19\% of children in Anderson et $a ;^{25}$ most of these plans became less intense. In Maneker et $a l,{ }^{28}$ management plans changed for $91 \%$ of children who unexpectedly had low $\mathrm{SaO}_{2}\left(\mathrm{SaO}_{2}<92 \%\right) ; 90 \%$ of these were started on oxygen therapy. Management plans also changed for $43 \%$ of children who expectedly had low $\mathrm{SaO}_{2} ; 90 \%$ of these were started on oxygen. In Mower et al, ${ }^{29}$ after receiving pulse oximeter results, physicians ordered new diagnostic tests for $20 \%$ of children with $\mathrm{SaO}_{2}<95 \%$ and for $0.5 \%$ of children with $\mathrm{SaO}_{2} \geq 95 \%$; they ordered new treatments for $11 \%$ of children with $\mathrm{SaO}_{2}<95 \%$ and for $1 \%$ of children with $\mathrm{SaO}_{2} \geq 95 \%$.

\section{DISCUSSION}

Pulse oximeters are routinely used in high-income countries, but are implemented without consistent guidelines of when/how to use them and little research on how their routine use impacts health outcomes or resources. New programmes encouraging pulse oximeter use in low-income countries should address these inadequacies in the evidence base and promote evidencebased decision-making.

Only five studies, all before-after studies at high risk of bias, were identified. Potential dissimilarities in patient/location characteristics existed between time periods in two studies; ${ }^{26} 27$ there were no independent controls in three, ${ }^{25} 2829$ and in these, physicians were perhaps more inclined to respond to pulse oximetry because results were given after, not during, initial evaluations (unlike outside study settings). In the study providing mortality data, oxygen concentrators, training and other improvements were introduced with pulse oximeters; ${ }^{27}$ while this study points to important effects of improving oxygen therapy systems, from identification to management, it provides only indirect information on possible effects of widescale pulse oximetry adoption, for example, primary care facilities for guiding referral. Other challenges in generalising the findings are that the studies were conducted in the USA and Papua New Guinea and none were conducted in primary care facilities. Although the data are drawn from US studies and those conducted over 15 years ago, available results have some value as they suggest how pulse oximeter introduction impacts physicians' decision-making, the key mechanism by which pulse oximetry influences practice.

Study design limitations reduce our confidence in the included studies' effect estimates. However, there is some evidence to indicate that pulse oximetry may lead to improved health outcomes, with lower mortality rates (when combined with improved/adequate oxygen administration) and reduced time in ED triage; pulse oximetry may change physicians' decisions regarding illness severity, and increase hospital admissions related to previously unrecognised hypoxaemia (note: hypoxaemia definitions varied from $<92 \%$ to $95 \%$ ). Routine pulse oximetry may also influence diagnostic tests and treatments used. Mower et $a,^{29}$ argue that physicians generally accurately judged $\mathrm{SaO}_{2}$ clinically when very high or low, but made more management changes when moderately low.

It is unclear from the literature how pulse oximetry impacts resource utilisation, even though pulse oximetry campaigns focus on low-income settings, where cost-effectiveness is crucial.

In Maneker et $a l,{ }^{28}$ and Mower et al, ${ }^{29}$ pulse oximetry increased resource use through increased admissions and oxygen 
Figure 2 Simple, hypothetical illustration of introducing pulse oximetry into primary care or walk-in clinical settings illustrating the trade-offs that may be apparent in terms of increased or decreased referral or admission rates based on plausible (low and high) estimates of existing rates and true prevalence of hypoxaemia. Note that in low-income countries children often have multiple acute respiratory infections (ARI) episodes per year. The estimates for the baseline (when pulse oximeters are not used) were the following: low estimate for referral rates from primary care facilities: $100(1 \%)$; high estimate: $500(5 \%)$; low estimate for admission from emergency department (ED): 500 (5\%); high estimate: 1500 (15\%). Referral and admission rates for when estimated by assuming an increase or decrease in primary care referrals/ED admissions of $5-50 \%$ over or below the baseline referral/admission rates. Hypoxaemia prevalence in children aged 7 days -36 months presenting to an ED with ARI has been shown to be as high as $59 \%{ }^{31}$ (when hypoxaemia defined as $\mathrm{SaO}_{2}<91 \%$ ) so these high estimates for referral/admission rates are reasonable. Referral/admission rates would be higher in a population if: the true hypoxaemia prevalence in the population is higher (eg, due to high altitude, seasonal effects on bronchiolitis, predisposing environmental factors for asthma); a larger proportion of hypoxaemic children are being missed by clinical evaluation; or higher thresholds are used to define hypoxaemia. The converse of these conditions would lead to lower referral/admission rates, as would a reduction in the number of false-positives as a result of improved accuracy of hypoxaemia diagnosis over clinical signs. pulse oximeters are used were
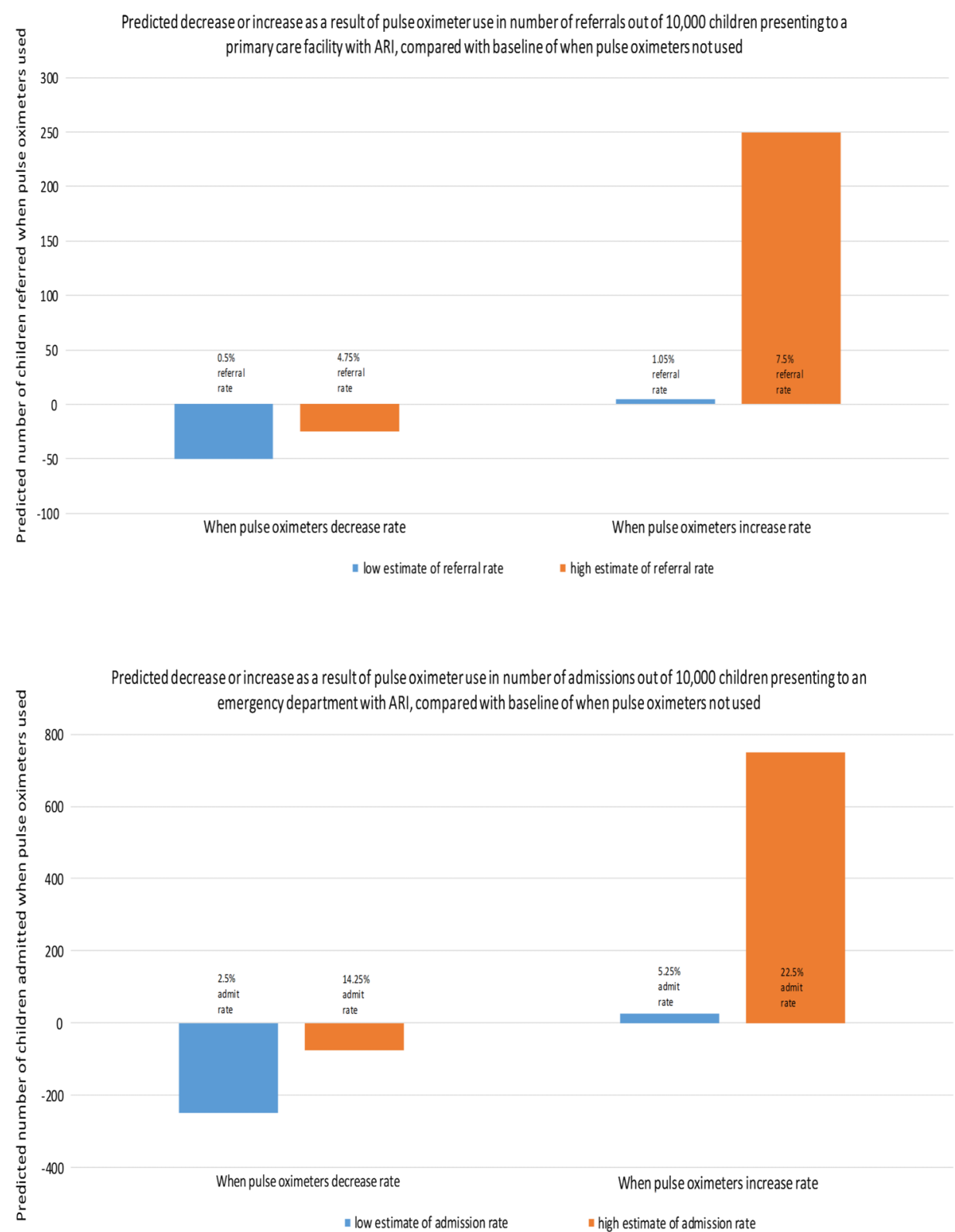

therapy for children with otherwise undetected hypoxaemia. Pulse oximetry led to reduced resource utilisation in two studies: in Anderson et $a l^{25}$ two-thirds of children whose illness severity scores changed were then considered less severely ill, and two-thirds of children whose management plans changed were then managed less aggressively; in Choi and Claudius, ${ }^{26}$ pulse oximetry led to reduced triage time.

Pulse oximetry could facilitate quicker diagnosis, so effective treatment starts earlier and recovery likelihood increases, reducing future resource use. Oximetry can reduce resource waste by indicating when to end treatment, and by decreasing falsepositives. However, in Schroeder et al, ${ }^{30}$ hospital stays were on average 1.6 days longer because of pulse oximetry as $26 \%$ of children met discharge criteria except needing oxygen according to pulse oximeters. If additional treatment was unnecessary (eg, inappropriate thresholds were used), then resources were wasted (as the authors assumed). However, if pulse oximetry enabled detection of hypoxic children who would not otherwise obtain treatment, then the additional resources were justified.

Although not discussed here, pulse oximetry also has important resource implications in outpatient facilities, where hypoxaemia prevalence in children, while lower than in hospitals, is still considerable (eg, 4-12\%), ${ }^{2}$ and where pulse oximetry could facilitate timely recognition of necessary care or referral to hospital. Figure 2 illustrates the range of effects of introducing pulse oximetry.

Randomly assigning health facilities to pulse oximeter introduction (with training) or no pulse oximetry could provide robust data on resource use (admissions, diagnostic tools, treatments, referrals, length of stay), health outcomes (mortality, morbidity, re-presentations), and which thresholds, if any, would be most effective for treatment initiation, if studies were sufficiently large. Such pragmatic studies could be done alongside implementation programmes and could elucidate whether pulse 
Table 2 Summary of findings

Pulse oximeters versus no pulse oximeters to inform diagnosis and treatment (excluding operative surgical care)

Population: newborns, children and adolescents aged up to 19 years

Intervention: pulse oximeter readings

Control: populations with no pulse oximeter readings

Outcomes: mortality rates, morbidity, length of hospital stay

\begin{tabular}{|c|c|c|c|c|c|}
\hline Outcomes & $\begin{array}{l}\text { Overall outcome difference between } \\
\text { control and intervention group }\end{array}$ & $\begin{array}{l}\text { Number of } \\
\text { participants by } \\
\text { outcome (studies) }\end{array}$ & $\begin{array}{l}\text { Relative effect } \\
\text { (with } 95 \% \mathrm{Cl} \text { ) }\end{array}$ & $\begin{array}{l}\text { Absolute effect } \\
\text { (with } 95 \% \mathrm{Cl} \text { ) }\end{array}$ & $\begin{array}{l}\text { Quality of } \\
\text { the evidence- } \\
\text { Grade }\end{array}$ \\
\hline Mortality rates & $\begin{array}{l}\text { The introduction of pulse oximeters alone may } \\
\text { lead to a reduction in mortality rates. }{ }^{27}\end{array}$ & $11291^{27}$ & $\begin{array}{l}\text { RR: } 0.648(0.533 \text { to } \\
0.788)\end{array}$ & $\begin{array}{l}\text { Reduction of } 1.75 \% \\
\text { (1.101 to } 2.398 \text { ) or } 17 \\
\text { fewer deaths per } 1000 \\
\text { patients }\end{array}$ & Very low* \\
\hline Morbidity: & When pulse oximeter results are obtained in the & $2564^{2529}$ & n/a & $\mathrm{n} / \mathrm{a}$ & Very lowt \\
\hline
\end{tabular}

$E D$, the assessed degree of illness and the diagnosis for children may be different than if pulse oximeter results are not obtained. This is especially the case for children who do not have a diagnosis of 'well', 'minor orthopaedic injuries' or 'minor surgical injuries', and/or is more likely in children who have low $\mathrm{SaO}_{2}$ values. ${ }^{25} 29$

Length of hospital stay

\section{The introduction of pulse oximetry into triage may} decrease the average time children spend in triage and may increase the proportion of hypoxic children who are admitted. ${ }^{262829}$

Secondary research question: treatment and management
When pulse oximeter results are obtained in the $E D$, the management plans for children may be different than if pulse oximeter results are not obtained. This is especially the case for children who do not have a diagnosis of 'well', 'minor orthopaedic injuries' or 'minor surgical injuries', and/or is more likely in children who have low $\mathrm{SaO}_{2}$ values, particularly if these are unexpectedly low. 252829
2564

-

Time spent in triage: Mean difference: $50 \mathrm{~min}(5.405$ to 94.595) Proportion of hypoxic children admitted: $n / a$ $\mathrm{n} / \mathrm{a}$
Time spent in triage: 17 fewer minutes spent in triage per $100 \mathrm{~min}$ Proportion of hypoxic children admitted: $n / a$

n/a
Very low

$2633^{252829}$

See online supplementary appendix IV for a more detailed summary of findings table.

${ }^{*}$ Non-controlled before-after study: Study limitations - there is a high risk of bias as the Duke et al ${ }^{27}$ study had a serious risk of bias, due mainly to the fact that oxygen concentrators and training were introduced into the study hospitals concurrently with pulse oximeters so it is not possible to determine how much of the change in mortality rates shown in the study was due specifically to pulse oximeter use; indirectness - the study was looking at the impact of the introduction of pulse oximeters and oxygen concentrators on mortality rates, rather than just the introduction of pulse oximeters alone; imprecision — only one study (and it did not report Cls for the measure of interest); this outcome has therefore been downgraded from Low to Very Low.

†Non-controlled before-after studies: Study limitations-there is a high risk of bias as both of these studies had a serious risk of bias, because the physicians in both studies were aware of the intervention status of the participants and so may have been more likely to take the pulse oximeter results into account than had they received the pulse oximeter results during their initial evaluations; in addition the authors of Mower et a ${ }^{29}$ excluded $20 \%$ of children who could have been included in the study, potentially affecting the results, and the authors of Anderson et $a^{25}$ excluded a subgroup of children from the analyses when it became evident that pulse oximeter results did not impact their management, so the study's results of pulse oximeter impact were exaggerated; indirectness-the changes in degree of illness and diagnosis shown in these studies are not actual changes in morbidity, they are changes in physicians' perceptions of morbidity; also both studies were looking at different suboutcomes and different subgroups from each other, most of which were not directly relevant to, or only partially relevant to, the review; imprecision—only two studies (neither of which reported any CIs); this outcome has therefore been downgraded from Low to Very Low.

¥Non-controlled before-after studies: Study limitations-there is a high risk of bias as two of the studies had a serious risk of bias, because the physicians in both studies were aware of the intervention status of the participants and so may have been more likely to take the pulse oximeter results into account than had they received the pulse oximeter results during their initial evaluations; in addition $20 \%$ and $32 \%$ of potential participants were not included in the Mower et $a l^{29}$ and Maneker et al ${ }^{28}$ studies, respectively, potentially affecting the results; indirectness-the outcomes investigated in the three studies (length of stay in emergency department (ED) triage, and \% admitted) are indirectly related to but not exactly the same as, the outcome of length of hospital stay; imprecision — only three studies (none of which reported any CIs); this outcome has therefore been downgraded from Low to Very Low. $\S$ Non-controlled before-after studies: Study limitations-there is a high risk of bias as all three of these studies had a serious risk of bias, because the physicians in all three studies were aware of the intervention status of the participants and so may have been more likely to take the pulse oximeter results into account than had they received the pulse oximeter results during their initial evaluations; in addition $20 \%$ and $32 \%$ of potential participants were not included in the Mower $e t a^{29}$ and Maneker et a ${ }^{28}$ studies, respectively, potentially affecting the results; also the authors of Anderson et a ${ }^{25}$ excluded a subgroup of children from the analyses when it became evident that pulse oximeter results did not impact their management, so the study's results of pulse oximeter impact were exaggerated; indirectness-the secondary research question considered the impact of pulse oximeter use on the proportion of children receiving oxygen therapy-only one of the studies actually reported the number of children in both groups who received oxygen therapy while the other two studies only reported results on outcomes that are related to oxygen therapy, by, like oxygen therapy, being examples of treatment and management; also all three studies were looking at different suboutcomes and different subgroups from each other, most of which were not directly relevant to, or only partially relevant to, the review; imprecision-only three studies (none of which reported any $\mathrm{Cls}$ ); this outcome has therefore been downgraded from Low to Very Low.

oximetry impacts resource use and health outcomes within costeffectiveness analyses.

If evidence suggests pulse oximetry increases resource utilisation then health workers, facility managers and public health practitioners would need to weigh cost-benefit trade-offs between using scarce resources on pulse oximetry or on other interventions. Context-specific formal cost- effectiveness analyses could be performed to help address these issues but these are rarely done when technologies are introduced into low-income countries' health systems. Such research should be independent and transparent evaluations feeding into wider, evidence-based and inclusive processes for decision-making on resource allocation within health systems. 
More research is also needed on the best ways to use pulse oximeters, particularly concerning $\mathrm{SaO}_{2}$ thresholds.

In high-income settings, disease management guidelines rarely recommend $\mathrm{SaO}_{2}$ thresholds for diagnosing, evaluating or monitoring children. ${ }^{12} 13$ When specific $\mathrm{SaO}_{2}$ thresholds are recommended, they differ across organisations, even though WHO's 2012 Recommendations for Management of Common Childhood Conditions provide clear guidance that oxygen be administered if $\mathrm{SaO}_{2}<90 \%$ (for children at $\leq 2500 \mathrm{~m}$ ). ${ }^{14}{ }^{15}$ Conversely, the Canadian Paediatric Society warns "it is important to recognize that setting arbitrary thresholds for oxygen therapy will influence admission rates". ${ }^{16}$ Setting thresholds is complicated because pulse oximeter results may not be considered in isolation from clinical findings, $\mathrm{SaO}_{2}$ can naturally fluctuate over a day, and studies show that 'healthy' $\mathrm{SaO}_{2}$ differs by age and altitude. ${ }^{20-22} 32 \mathrm{~A}$ few studies have investigated whether outcomes are comparable when thresholds higher than WHO's $<90 \%$ are used: Cunningham et $a l^{33}$ found cough resolution time in children with bronchiolitis was equivalent when a $<94 \%$ or $<90 \%$ threshold was used for oxygen therapy while Lazzerini et $a l,{ }^{34}$ found that hypoxaemia predicted elevated mortality risk in children with acute lower respiratory infection when a $<92 \%$ or $<90 \%$ hypoxaemia threshold was used. It is therefore perhaps unexpected that no studies have examined health system consequences of implementing the WHO guidance of using $\mathrm{SaO}_{2}<90 \%$ thresholds.

In absence of clear guidelines, opinion differs on which thresholds should indicate hypoxaemia and prompt admission, referral, oxygen therapy or other treatments. When emergency physicians were surveyed, there was considerable variability in the lowest $\mathrm{SaO}_{2}$ for which they would discharge a 2-year-old with pneumonia and a 10-month-old with bronchiolitis. ${ }^{18}$ Maneker et $a l^{28}$ and Mower et al, ${ }^{29}$ defined low $\mathrm{SaO}_{2}$ as $\leq 92 \%$ and $<95 \%$ respectively, thus reducing results comparability.

Threshold choice can substantially impact health system outcomes; thus in Schuh et al's ${ }^{35}$ randomised clinical trial of infants (excluded from this review because all children received pulse oximeter readings), admission rates were sensitive to small saturation differences: $41 \%$ of children in the control group were admitted within $72 \mathrm{~h}$ versus $25 \%$ of children whose displayed $\mathrm{SaO}_{2}$ s were artificially increased by $3 \%$.

\section{CONCLUSIONS}

Pulse oximeters are routinely used in high-income countries and international organisations are investing in programmes to promote pulse oximetry in low-income countries, but there is little evidence, from any region or setting, on the impact or optimal use of pulse oximeters when children present to a health facility. More research is needed on how pulse oximetry impacts health outcomes and services, how knowledge of $\mathrm{SaO}_{2}$ should be integrated with other clinical findings, whether defining 'one-size fits all' thresholds is possible or even useful, for hypoxaemia and in diagnosing/monitoring specific diseases, and how pulse oximetry affects resource utilisation. Such pragmatic research could accompany pulse oximeter implementation efforts and would provide much needed evidence.

\section{Twitter Follow Abigail Enoch at @AbbyEnoch}

Acknowledgements The authors thank Trevor Duke for his advice and assistance with the topic and background; Nia Roberts for her advice on systematic searching methods; and Orlaith Burke for her assistance with the statistical methods.

Contributors AJE drafted the initial protocol with the assistance of SS and ME; AJE carried out the systematic review, SS and ME read through full texts of potential studies and advised on the bias assessments; AJE drafted the initial report and all authors contributed to its development and approved the final version.

Funding AJE is the recipient of a studentship jointly funded by the Medical Research Council and the Oxford Nuffield Department of Population Health; ME is supported by funds from a Wellcome Trust Senior Fellowship (\#097170). SS is supported by Oxford's Nuffield Department of Population Health.

Competing interests None declared.

Provenance and peer review Not commissioned; internally peer reviewed.

Open Access This is an Open Access article distributed in accordance with the terms of the Creative Commons Attribution (CC BY 4.0) license, which permits others to distribute, remix, adapt and build upon this work, for commercial use, provided the original work is properly cited. See: http://creativecommons.org/ licenses/by/4.0/

\section{REFERENCES}

1 World Health Organization. Manual on use of oxygen therapy in children. 2014. http://www.who.int/maternal_child_adolescent/documents/child/en/.

2 Lozano JM. Epidemiology of hypoxaemia in children with acute lower respiratory infection [oxygen therapy in children]. Int J Tuberc Lung Dis 2001;5:496-504.

3 Djelantik IG, Gessner BD, Sutanto A, et al. Case fatality proportions and predictive factors for mortality among children hospitalized with severe pneumonia in a rural developing country setting. J Trop Pediatr 2003;49:327-32.

4 Orimadegun A, Ogunbosi B, Orimadegun B. Hypoxemia predicts death from severe falciparum malaria among children under 5 years of age in Nigeria: the need for pulse oximetry in case management. Afr Health Sci 2014;14:397-407.

5 Desalu 00, Onyedum CC, Iseh KR, et al. Asthma in Nigeria: are the facilities and resources available to support internationally endorsed standards of care? Health Policy 2011:99:250-4.

6 English M, Gathara D, Mwinga S, et al. Adoption of recommended practices and basic technologies in low-income setting. Arch Dis Child 2014;99:452-6.

7 Lifebox. Value of a lifebox. http://www.lifebox.org/safe-surgery/value-of-a-lifebox/ (accessed May 2015).

8 Peterson $\mathrm{CL}$, Chen TP, Ansermino M, et al. Design and evaluation of a low-cost smartphone pulse oximeter. Sensors (Basel) 2013;13:16882-93.

9 World Health Organization. Global pulse oximetry project: First international consultation meeting. Background document. 2008. http://www.who.int/ patientsafety/events/08/1st_pulse_oximetry_meeting_background_doc.pdf (accessed Aug 2015).

10 Feinmann J. Pulse oximeters for all. BMJ 2011;343:d8085.

11 Hanning CD, Alexander-Williams JM. Fortnightly review: pulse oximetry: a practical review. BMJ 1995;311:367

12 Bronchiolitis in children: NICE guideline, draft for consultation. 2014. http://www. nice.org.uk/guidance/ng9/documents/bronchiolitis-in-children-draft-nice-guideline2 (accessed April 2015).

13 Guidelines for the management of community acquired pneumonia in adults. British Thoracic Society 2009. https://www.brit-thoracic.org.uk/document-library/clinicalinformation/pneumonia/adult-pneumonia/a-quick-reference-guide-bts-guidelines-forthe-management-of-community-acquired-pneumonia-in-adults/ (accessed April 2015).

14 Guidelines for the use of pulse oximeters. NHS Calderdale CCG, NHS Greater Huddersfield CCG, NHS North Kirklees CCG, NHS Wakefield CCG. 2013. http:// www.greaterhuddersfieldccg.nhs.uk/fileadmin/greaterhuddersfield/Medicines_ Management/Pulse_Oximetry_guidelines_181013.pdf (accessed April 2015).

15 Recommendations for management of common childhood conditions. World Health Organization. 2012. http://whqlibdoc. who.int/publications/2012/9789241502825_ eng.pdf (accessed Aug 2015)

16 Friedman JJ, Rieder MJ, Walton JM. Bronchiolitis: recommendations for diagnosis, monitoring and management of children one to 24 months of age. Paediatr Child Health 2014;19:485-91.

17 Ralston SL, Lieberthal AS, Meissner HC, et al. Clinical practice guideline: the diagnosis, management, and prevention of bronchiolitis. Pediatrics 2014;134: e1474-502.

18 Brown L, Dannenberg B. Pulse oximetry in discharge decision-making: a survey of emergency physicians. CJEM 2002;4:388-93.

19 Ingram G, Munro M The use (or otherwise) of pulse oximetry in general practice. Br J Gen Pract 2005;55:501-2.

20 Fouzas S, Priftis KN, Anthracopoulos MB. Pulse oximetry in pediatric practice. Pediatrics 2011;128:740-52.

21 Schult S, Canelo-Aybar C. Oxygen saturation in healthy children aged 5 to 16 years residing in Huayllay, Peru at 4340m. High Alt Med Biol 2011;12:89-92.

22 Subhi $R$, Smith $K$, Duke T. When should oxygen be given to children at high altitude? A systematic review to define altitude-specific hypoxaemia. Arch Dis Child 2009;94:6-10.

23 13a good practice data extraction form. EPOC resources for review authors. Oslo: Norwegian Knowledge Centre for the Health Services: Effective Practice and 
Organisation of Care (EPOC). 2014. https://epocoslo.cochrane.org/ epoc-specific-resources-review-authors (accessed April 2015).

24 Sterne JAC, Higgins JPT, Reeves BC, on behalf of the development group for ACROBAT-NRSI. A Cochrane risk of bias assessment tool: For non-randomized studies of interventions (ACROBAT-NRSI). 2014. https://sites.google.com/site/ riskofbiastool/ (accessed Apr 2015).

25 Anderson $A B$, Zwerdling RG, Dewitt TG. The clinical utility of pulse oximetry in the pediatric emergency department setting. Pediatr Emerg Care 1991;7:263-6.

26 Choi J, Claudius I. Decrease in emergency department length of stay as a result of triage pulse oximetry. Pediatr Emerg Care 2006;22:412-14.

27 Duke T, Wandi F, Jonathan $\mathrm{M}$, et al. Improved oxygen systems for childhood pneumonia: a multihospital effectiveness study in Papua New Guinea. Lancet 2008:372:1328-33

28 Maneker AJ, Petrack EM, Krug SE. Contribution of routine pulse oximetry to evaluation and management of patients with respiratory illness in a pediatric emergency department. Ann Emerg Med 1995;25:36-40.

29 Mower WR, Sachs C, Nicklin EL, et al. Pulse oximetry as a fifth pediatric vital sign. Pediatrics 1997;99:681-6.
30 Schroeder AR, Marmor AK, Pantell RH, et al. Impact of pulse oximetry and oxygen therapy on length of stay in bronchiolitis hospitalizations. Arch Pediatr Adolesc Med 2004; 158:527-30.

31 Onyango FE, Steinhoff MC, Wafula EM, et al. Hypoxaemia in young Kenyan children with acute lower respiratory infection. BMJ 1993; 306:612-15.

32 Vargas MH, Heyaime-Lalane J, Perez-Rodriguez L, et al. Day-night fluctuation of pulse oximetry: an exploratory study in pediatric inpatients. Rev Invest Clin 2008;60:303-10.

33 Cunningham $\mathrm{S}$, Rodriguez $\mathrm{A}$, Adams $\mathrm{T}$, et al. Oxygen saturation targets in infants with bronchiolitis (BIDS): a double-blind, randomised, equivalence trial. Lancet 2015:386:1041-8.

34 Lazzerini M, Sonego M, Pellegrin MC. Hypoxaemia as a mortality risk factor in acute lower respiratory infections in children in low and middle-income countries: systematic review and meta-analysis. PlOS ONE 2015; 10:e0136166.

35 Schuh S, Freedman S, Coates $A$, et al. Effect of oximetry on hospitalization in bronchiolitis: a randomized clinical trial. JAMA 2014;312:712-18. 